\title{
ArcheoSciences
}

Revue d'archéométrie

33 (suppl.) | 2009

Mémoire du sol, espace des hommes

\section{Three-dimensional structure of a highly heterogeneous soil horizon derived by Electrical Resistivity Tomography}

I. Cousin, A. Frison, G. Giot, Hocine Bourennane, Roger Guérin and G. Richard

\section{CpenEdition}

\section{Journals}

Electronic version

URL: https://journals.openedition.org/archeosciences/1702

DOI: 10.4000/archeosciences. 1702

ISBN: 978-2-7535-1599-4

ISSN: 2104-3728

Publisher

Presses universitaires de Rennes

\section{Printed version}

Date of publication: 30 October 2009

Number of pages: 279-281

ISBN: 978-2-7535-0943-6

ISSN: $1960-1360$

\section{Electronic reference}

I. Cousin, A. Frison, G. Giot, Hocine Bourennane, Roger Guérin and G. Richard, "Three-dimensional structure of a highly heterogeneous soil horizon derived by Electrical Resistivity Tomography", ArcheoSciences [Online], 33 (suppl.) | 2009, Online since 30 October 2011, connection on 01 February 2022. URL: http://journals.openedition.org/archeosciences/1702 ; DOI: https://doi.org/10.4000/ archeosciences. 1702 


\title{
Three-dimensional structure of a highly heterogeneous soil horizon derived by Electrical Resistivity Tomography
}

\author{
I. Cousin*, A. Frison*, G. Giot*, H. Bourennane*, \\ R. GUÉRIN ** and G. Richard*
}

Key words: Soil structure, Electrical resistivity, Heterogeneity, 3D.

\section{INTRODUCTION}

The soil consists in a natural filter of water transfer to the groundwater. Its structure influences water storage and transfer properties or gas diffusivity, which induce major consequences on both environment and agronomy. Knowing the soil structure is thus essential to predict the soil hydraulic functioning and the $3 \mathrm{D}$ characterization of the structure at the horizon scale is necessary to describe the hydraulic functioning of the soil. In heterogeneous horizons, the structure (n scale) is defined by the arrangement of Elementary Pedological Volumes [(n-1) scale], EPV. The objective of this paper is to describe the three-dimensional structure of a heterogeneous horizon by $2 \mathrm{D}$ and $3 \mathrm{D}$ electrical resistivity prospectings.

\section{MATERIAL AND METHODS}

\section{Experimental site}

The studied soil is located on the crest of the Yonne plateau, France, in a cultivated field. The studied soil is an Albeluvisol developed in Quaternary loam of Aeolian origin deposited over an Eocene clay layer. It comprises three horizons. Among them, from 0.35 to $0.60 \mathrm{~m}$ depth, a transitional $\mathrm{E} \& \mathrm{Bt}$ horizon, that exhibits the maximum heterogeneity in structure (Figure 1). This horizon has a polyhedral structure characterized by the juxtaposition of different elementary pedological volumes: silty white volumes and ochre clay volumes. The white volumes usually consist in vertical tongues in the ochre matrix.

\section{Electrical resistivity measurements}

Before the electrical measurements, the ploughed horizon was removed to obtain a regular and a planar surface of about one square meter at the upper surface of the $\mathrm{E} \& \mathrm{Bt}$ horizon. Electrical measurements were first realised on this plane (depth $=0.35 \mathrm{~m}-\mathrm{A}$ level). After these measurements, a $0.06 \mathrm{~m}$ layer of soil was removed and a second sequence of electrical was made (depth $=0.41-\mathrm{B}$ level). The same procedure was repeated to get a third planar surface (depth $=0.47-\mathrm{C}$ level). A orthogonal repair was considered: the $\mathrm{x}$ - and $\mathrm{y}$ - direction were parallel to the soil surface and the $\mathrm{z}$ direction was perpendicular to the soil surface.

*INRA, UR0272 Science du Sol, Centre de recherche d'Orléans, 2163 Avenue de la Pomme de Pin, CS 40001 Ardon, F-45075 Orléans cedex 2, France.

** Université Pierre et Marie Curie, UMR 7619 Sisyphe, tour 56, couloir 56-46, $3^{e}$ étage case 105, 75252 Paris Cedex 05, France. 


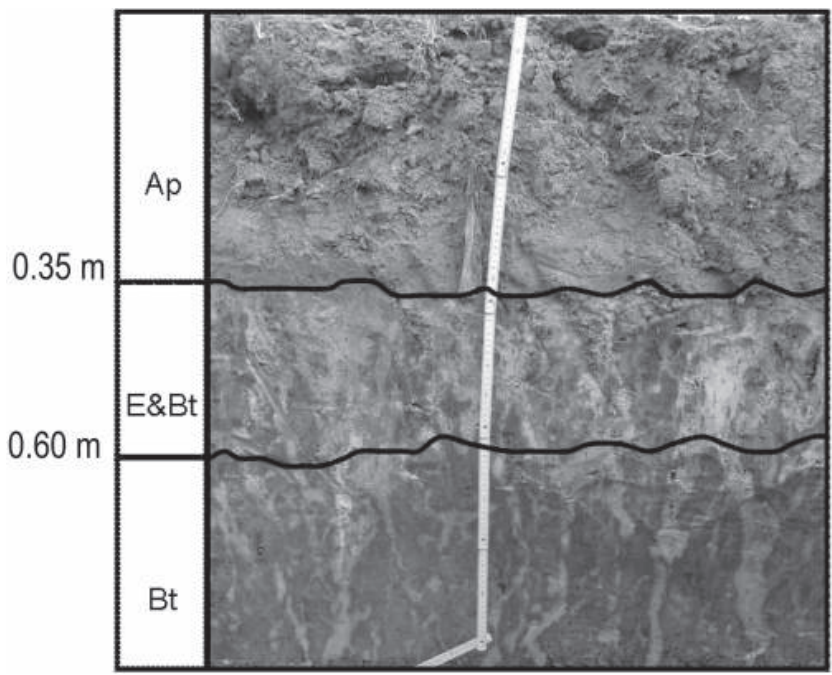

Figure 1: A picture of the soil profile studied. The E \& BT horizon, that is of interest in this study, is located between 0.35 and $0.60 \mathrm{~m}$ depth.

On the A level, seven Wenner profiles, were realised in the $\mathrm{x}$ - direction with 32 electrodes spaced $0.03 \mathrm{~m}$ apart (W32 arrays). These Wenner profiles were $0.09 \mathrm{~m}$ spaced apart. The same procedure of measurements with the W32 array was repeated on the B level, and the $\mathrm{C}$ level. The $\mathrm{x}$ and $\mathrm{y}$ coordinates of each W32 array did not change and the $\mathrm{z}$ coordinate was equal to $0.06 \mathrm{~m}$ for the $\mathrm{B}$ level and $0.12 \mathrm{~m}$ for the $\mathrm{C}$ level.

For the $\mathrm{A}$ and $\mathrm{C}$ levels, four Wenner profiles, were realised in the y direction with 16 electrodes spaced $0.03 \mathrm{~m}$ apart (W16 array).

At the A and C levels, a 3-D survey was realised by using a square array configuration with 32 electrodes. Four electrodes, arranged in a square with borders parallel to the $\mathrm{x}$ - and $y$ - directions, were used for one measurement of the apparent electrical resistivity; the latter was measured along two orientations, parallel to the $\mathrm{x}$ - axis or parallel to the $\mathrm{y}$-axis, to take into account the anisotropy of the soil. The electrode spacing was equal to $0.09 \mathrm{~m}$.

\section{Protocol of inversion}

For each level, a complete dataset of apparent resistivity measurements (Wenner and square arrays) was build. It comprised the measurements with the W32, W16 and square arrays configurations. Each dataset was then inverted with the RES3DINV model (Loke \& Barker, 1996) and the complete 3-D interpreted data was built. It resulted in a $0.94 \mathrm{~m}$ (x-direction) $\mathrm{x} 0.54 \mathrm{~m}$ (y-direction) $\mathrm{x} 0.20 \mathrm{~m}$ (z-direction) volume.

\section{RESUlTS AND DISCUSSION}

\section{Apparent resistivity data}

The resistivity generally decreased from the A level to the $\mathrm{C}$ level. On the A level, the apparent resistivity decreased significantly with depth. Moreover, on some profiles, the resistivity was higher for the positions $0.15<\mathrm{x}<0.45 \mathrm{~m}$, and for the first to the fourth pseudo-depths (Figure 2). On the $\mathrm{B}$ and $\mathrm{C}$ levels, the general decrease with depth was less pronounced. For the square array configuration, the heterogeneity was high for the first pseudo-depth whatever the

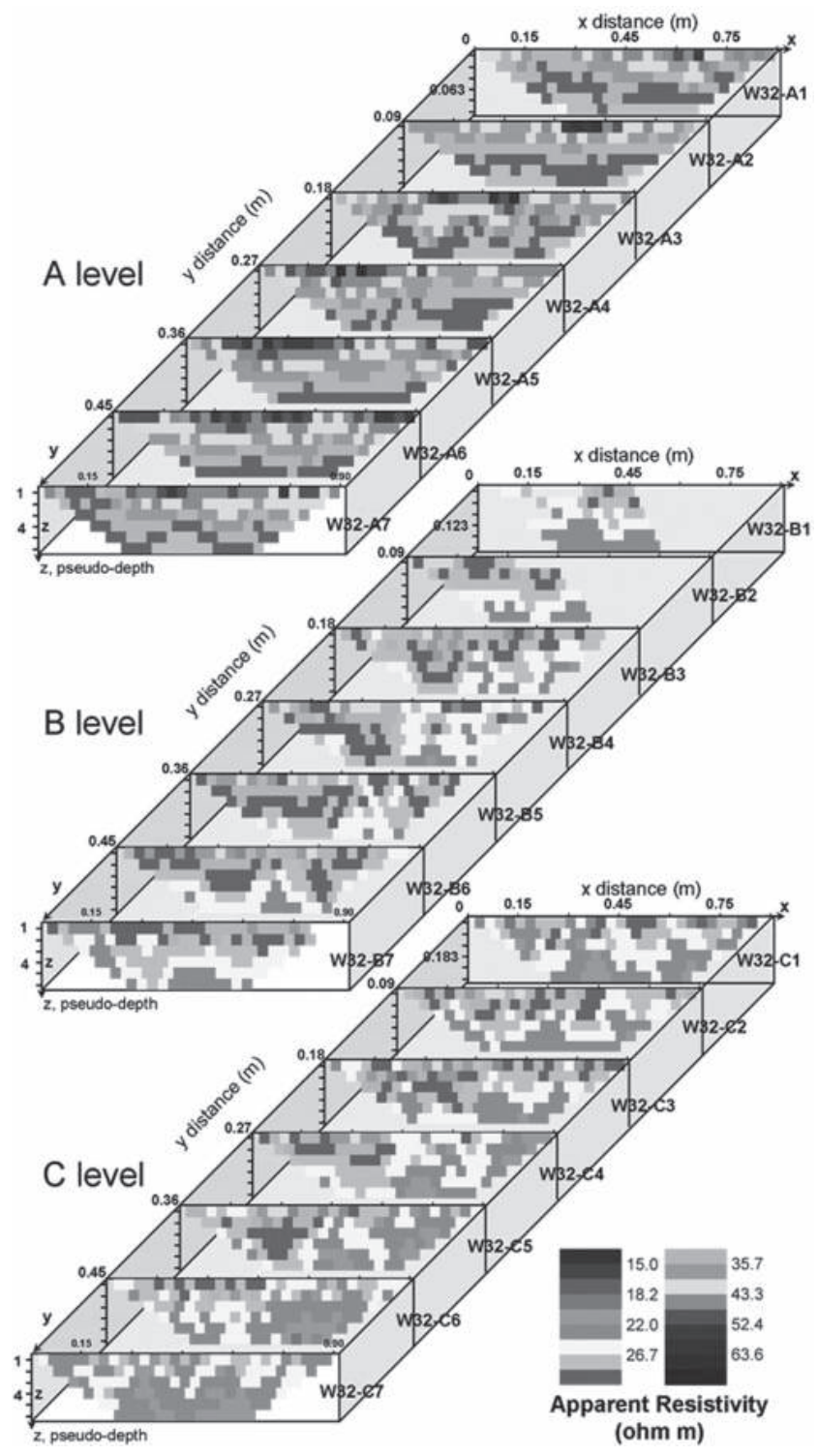

Figure 2 (see color plate): Apparent resistivity measurements from the W32 arrays at the three levels. 
level and the direction of injection for the current. No simple spatial organisation could be discussed from these data.

\section{Interpreted resistivity data and comparison with photographs of the real surface}

The 3D structure derived from interpreted electrical resistivity data exhibited large values of electrical resistivity - corresponding to white volumes - near the surface, along the $\mathrm{x}$-direction, i.e. parallel to the surface plane. At deeper positions, the large resistivity values were organised in geometrical volumes more oriented along the $\mathrm{z}$-direction, $i$. e. along a vertical axis (Figure 3). This is consistent with the

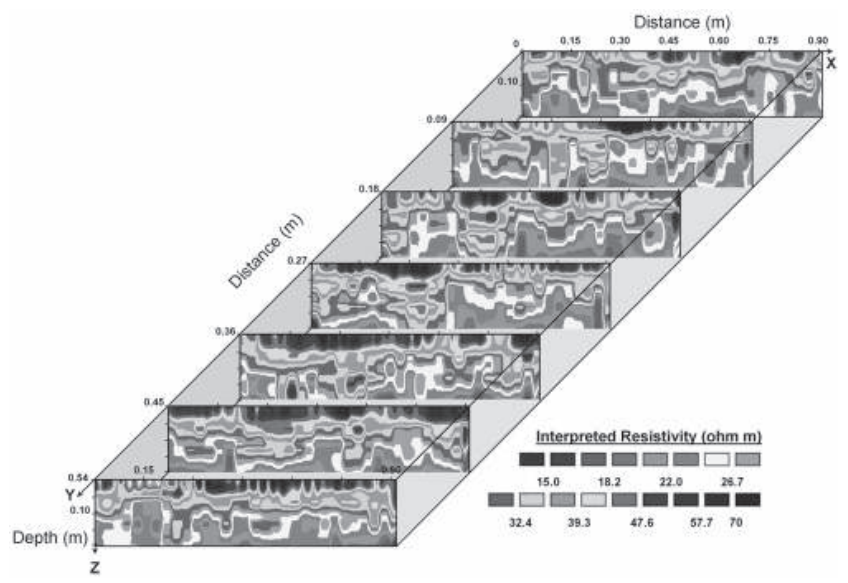

Figure 3 (see color plate): Interpreted resistivity data from the whole $3 \mathrm{D}$ dataset. The pictures represent $2 \mathrm{D}$ vertical profiles (that are more convenient for the interpretation). The white lines delineate areas with a higher electrical resistivity, corresponding to white elementary pedological volumes. general organisation of the $\mathrm{E} \& \mathrm{Bt}$ horizon of an Albeluvisol. Indeed, it exhibits more numerous white degraded volumes at its top, whereas, at deeper positions, the white volumes are less numerous and more vertical, invaginated into tongues whose size may vary from few centimetres to several tens of centimetres.

\section{Conclusion}

The studied horizon showed a complex structure composed by a juxtaposition of silty white elementary pedological volumes, and clayey ochre ones. We demonstrated that the $3 \mathrm{D}$ structure of the soil horizon could be derived from the electrical resistivity data, by using several 2D Wenner arrays and square arrays. This $3 \mathrm{D}$ structure was consistent with the real 3D structure observed in the field: some tongues of white degraded volumes were invaginated into more clayey-ochre volumes. Depending on their real texture, these tongues may be or not functional for water transfer. In the future, electrical resistivity measurements at several times during infiltration or evaporation periods could enable to identify the functional tongues.

\section{Référence}

LOKE M. H., BARKER R. D., 1996. Rapid least-squares inversion of apparent resistivity pseudosections using a quasi-Newton method. Geophysical Prospecting 44, 131-152. 